\title{
POWER FLOW STUDY FOR A MICROGRID BY USING MATLAB AND POWERWORLD SIMULATOR
}

\author{
Ahmet NUR ${ }^{1^{*}}$, Asim KAYGUSUZ ${ }^{2}$ \\ ${ }^{1}$ Department of Electrical-Electronics Engineering, Adiyaman University/Turkey \\ ${ }^{2}$ Department of Electrical-Electronics Engineering, Inonu University/Turkey \\ *anur@adiyaman.edu.tr
}

\begin{abstract}
In the near future, the use of energy sources such as solar and wind in power systems will increase. Microgrids are hybrid structures as formed the integration of renewable energy sources with conventional energy generation plants. Microgrids can provide uninterrupted energy for users. The power system must be operated correctly and effectively so that the power flow in the power system is continuous. The paper demonstrates a case study for a power flow analysis. First, the results were calculated and obtained in Matlab software by using the Gauss-Seidel method. Then the system was designed in the PowerWorld simulator and the success of both programs was examined.
\end{abstract}

Key words: Power Flow, Microgrid, Matlab, PowerWorld

\section{Introduction}

In recent years, changes in consumer demand and technololgy dependency in society has increased. The need for a reliable and fault-resistant electrical distribution network has become more and more important. A micro grid is an interconnected network of distributed energy systems that can function whether they are connected or independent from the main grid. Micro grid provides maximum utilization of existing energy and demand side management. It ensures that renewable and clean sources are included in the network. The microgrid is a reflection of the smart grid of the future [1-3].

The structure of the microgrid consists of energy sources such as wind turbines, micro turbines, fuel cells, PV modules etc. As shown in Figure 1, the energy sources are connected to the network via an interface unit such as a power electronic devices. Power electronic systems affect the quality of the system to which they are connected and require new control arrangements. Microgrid Central 
Controller (MGCC) is the main controller that controls Micro-source Controller (MC) and Load Controller (LC) [4].

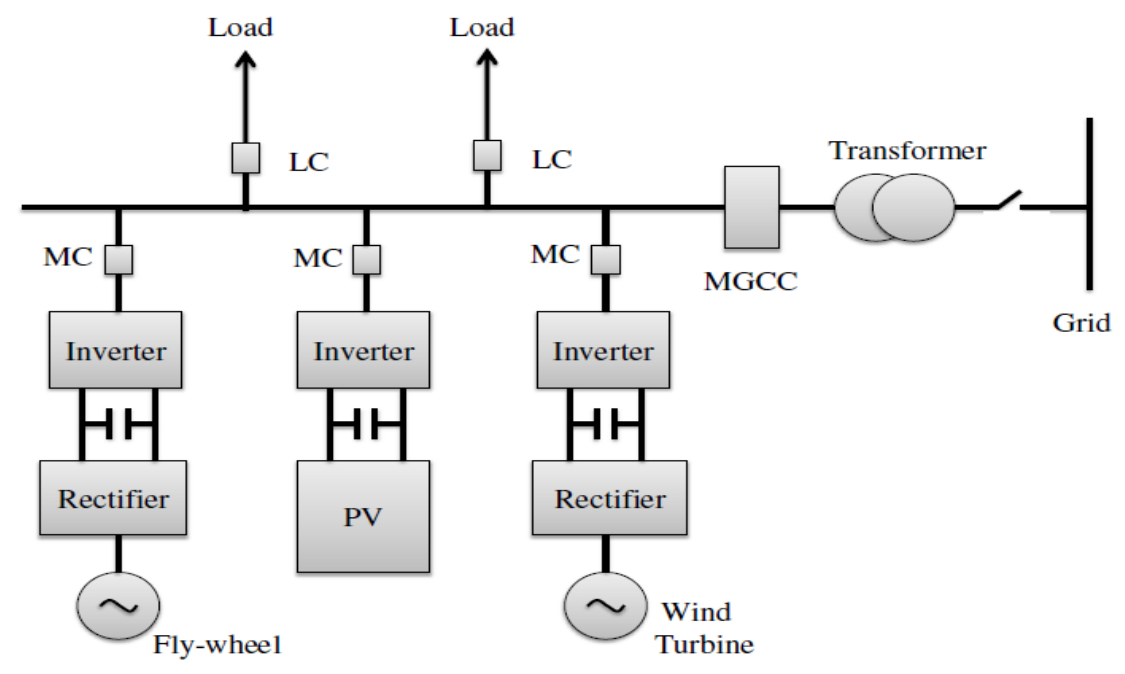

Figure 1. Structure of a Typical Microgrid [4]

$\checkmark$ Microgrids have many benefits. These benefits can be listed as follows [5, 6].

$\checkmark$ Environmental protection, especially in terms of reducing $\mathrm{CO}_{2}$ emissions

$\checkmark \quad$ Energy production diversity and supply security

$\checkmark$ Reduction in central power plants and losses

$\checkmark$ Having the possibility of rapid deployment and fast installation

$\checkmark$ The fuel is abundant, inexhaustible and free

$\checkmark$ Costs can be estimated because they are not influenced by fuel price fluctuations

$\checkmark$ Better network congestion management and power quality

$\checkmark$ Enabling development of green electricity

For this study, designed microgrid consists of wind turbine, PV, micro turbine and Pem Fuel Cell, main grid and load busses. The designed microgrid is shown in Figure 2. 


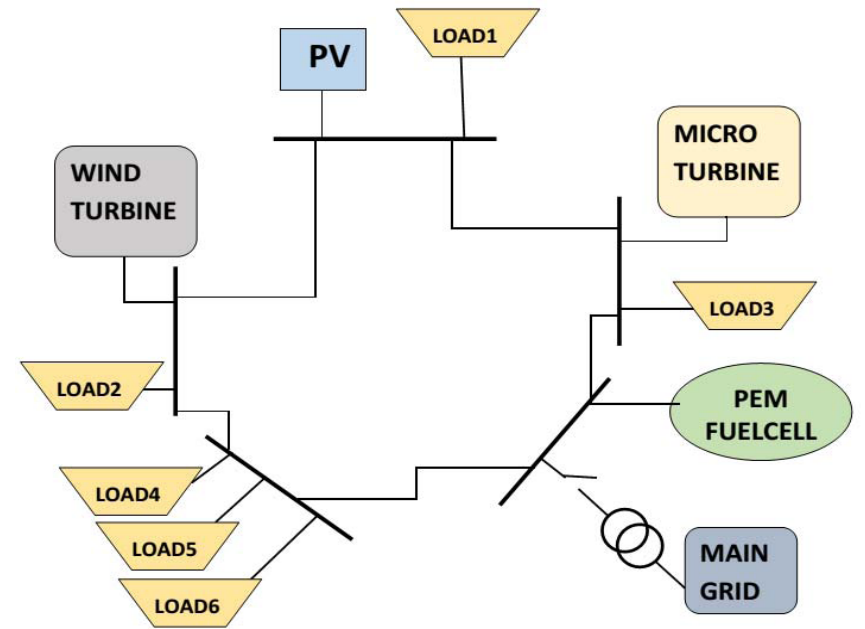

Figure 2. Designed Microgrid [7]

\section{Power Flow Analysis}

Power flow studies are one of the important tools in the operation, monitoring and control of power systems. In order to be able to evaluate the performance of power systems, it is necessary to perform power flow analysis under normal operating conditions and fault conditions such as short circuit. The purpose of power flow analysis is to determine the active-reactive power flows and the identification of voltages and currents. Iterative methods are used to solve nonlinear equations. Different mathematical techniques have been used to examine power flow analysis. These techniques are Newton-Raphson, Fast-Decoupled, and Gauss-Seidel methods [8, 9].

The Gauss-Seidel method is a well-known method among power flow analysis methods. The Gauss-Seidel method performs much better than other mathematical methods. In this method an initial value is guessed and the newly calculated value replaces the initial value. The iteration is stopped when the solution converges [10]. Consider a system of $n$ linear equations with $x$ unknowns

$A \boldsymbol{x}=\boldsymbol{b}$

where $A=\left(a_{i j}\right)_{n \times n}$ and $\boldsymbol{x}=\left(x_{1}, x_{2}, \ldots, x_{n}\right)^{T}$ and $\boldsymbol{b}=\left(b_{1}, b_{2}, \ldots, b_{n}\right)^{T}$.

After the computations, we can rewrite $(A x)$ as

$$
x_{i}^{(k+1)}=-\frac{1}{a_{i i}}\left[\sum_{j=1}^{i-1} a_{i j} x_{j}^{(k+1)}+\sum_{j=i+1}^{x} a_{i j} x_{j}^{(k)}-b_{i}\right] \quad \mathrm{i}=1,2, \ldots, \mathrm{n}
$$

It is assumed that the system operates under normal, balanced conditions and is represented by a single line diagram when the power flow problem is solved. The variables to be considered in each bus are voltage amplitude $(\mathrm{V})$, voltage phase angle $(\delta)$, active power $(\mathrm{P})$ and reactive power $(\mathrm{Q})$. As shown in table 1, the busses in a power system are divided into 3 groups: 
1. Load bus ; the active $(\mathrm{P})$ and reactive power $(\mathrm{Q})$ are known and where the amplitude of the bus voltage $(\mathrm{V})$ and phase angle $(\delta)$ are searched. The active and reactive power values are negative because power is consumed in the load bus.

2. Generator bus ; the active power (P) and the voltage amplitude (V) are known where the voltage phase angle $(\delta)$ and the reactive power $(\mathrm{Q})$ are searched.

3 . Swing bus (reference bus); the voltage amplitude (V) and phase angle ( $\delta$ ) are known where active power $(\mathrm{P})$ and reactive power $(\mathrm{Q})$ are searched. The difference between the power caused by the losses in the power system and the planned load is evaluated over this bus.

Table 1. Classification of Power System Busses

\begin{tabular}{|c|c|c|}
\hline Classification & Knowns & Unknowns \\
\hline Load Bus & $P, Q$ & $V, \delta$ \\
\hline Generator Bus & $P, V$ & $Q, \delta$ \\
\hline Swing Bus & $V, \delta$ & $P, Q$ \\
\hline
\end{tabular}

In a system with $\mathrm{N}$ busses, the expression given in eq. (1.3) continues to be computed until the difference between the bus voltages is smaller than the specified error value by the user. Here $\mathrm{n} \neq \mathrm{k}$. The voltage values on the right side of the equation are the latest values calculated for the bus. $\mathrm{Y}$ is the matrix of the bare admittance of the system. The impedances of the loads and the generators are not included but are calculated using the system line impedances $[11,12]$.

$V_{k}=\frac{1}{Y_{k k}}\left[\frac{P_{k}-j Q_{k}}{V_{k}^{*}}-\sum_{n=1}^{N} Y_{k n} V_{n}\right]$

\section{Matlab Application}

Matlab is a software that used mainly in the engineering sciences where numerical and analytical expressions of mathematical functions are used. The software is highly effective in numerical analysis, simulation, numerical and graphical solution techniques of engineering problems. The parameters for the sources, loads and lines used in the Matlab are shown in Table 2 and Table 3.

Table 2. Parameters For The Sources and Loads

\begin{tabular}{|c|c|c|}
\hline Component & Connected Bus & Power \\
\hline PV & Bus 1 & $2000 \mathrm{~W}$ \\
\hline Load 1 & Bus 1 & $2000 \mathrm{~W}-600 \mathrm{Var}$ \\
\hline Wind Turbine & Bus 2 & $2535 \mathrm{~W}$ \\
\hline Load 2 & Bus 2 & $12000 \mathrm{~W}$ \\
\hline Load 4 & Bus 3 & $12000 \mathrm{~W}$ \\
\hline Load 5 & Bus 3 & $8000 \mathrm{~W}$ \\
\hline Load 6 & Bus 3 & $10000 \mathrm{~W}$ \\
\hline Pem Fuelcell & Bus 4 & $1000 \mathrm{~W}$ \\
\hline
\end{tabular}




\begin{tabular}{|c|c|c|}
\hline Main Grid & Bus 4 & $34992 \mathrm{~W}$ \\
\hline Micro Turbine & Bus 5 & $9702 \mathrm{~W}-331 \mathrm{Var}$ \\
\hline Load 3 & Bus 5 & $6000 \mathrm{~W}$ \\
\hline
\end{tabular}

Table 3. Parameters For The Lines

\begin{tabular}{|c|c|c|c|c|}
\hline Source Bus & Target Bus & R & X & B \\
\hline Micro Turbine & Pem Fuelcell & 0.01273 & 0.0093 & 0.002 \\
\hline Wind Turbine & Load & 0.00636 & 0.00046 & 0.001 \\
\hline Pem Fuelcell & Load & 0.02546 & 0.0186 & 0.004 \\
\hline PV & Micro Turbine & 0.01273 & 0.0093 & 0.002 \\
\hline PV & Wind Turbine & 0.01273 & 0.0093 & 0.002 \\
\hline
\end{tabular}

After the power flow analysis is performed in Matlab program with Gauss-Seidel method, the following values are obtained. The number of iterations used for power flow analysis is 11 . Table 4 shows the results from the Matlab solution.

Table 4. Results from the Matlab Solution

\begin{tabular}{|c|c|c|c|c|c|c|}
\hline \multicolumn{2}{|c|}{ Line } & \multicolumn{2}{c|}{ Power at Busses and Lines } & \multicolumn{2}{c|}{ Line Losses } \\
\hline From & To & MW & Mvar & MVA & MW & Mvar \\
\hline 1 & & 0.225 & -0.678 & 0.715 & & \\
\hline & 2 & 16.327 & -1.072 & 16.363 & 0.034 & -0.373 \\
\hline & 5 & -16.083 & 0.366 & 16.087 & 0.033 & -0.375 \\
\hline 2 & & -9.465 & 2.122 & 9700 & & \\
\hline & 1 & -16.293 & 0.699 & 16.308 & 0.034 & -0.373 \\
\hline & 3 & 7.711 & 1.533 & 7.862 & 0.004 & -0.198 \\
\hline 3 & & -30.000 & 0.000 & 30.000 & & \\
\hline & 2 & -7.707 & -1.731 & 7.899 & 0.004 & -0.198 \\
\hline & 4 & -24.929 & 14.870 & 29.028 & 0.220 & -0.782 \\
\hline 4 & & 35.992 & 0.000 & 35.992 & & \\
\hline & 3 & 25.149 & -15.652 & 29.622 & 0.220 & -0.782 \\
\hline & 5 & 12.791 & -0.469 & 12.799 & 0.021 & -0.385 \\
\hline 5 & & 3.702 & -0.331 & 3.717 & & \\
\hline & 1 & 16.116 & -0.741 & 16.133 & 0.033 & -0.375 \\
\hline & 4 & 12.770 & 0.083 & 12.770 & 0.021 & -0.385 \\
\hline
\end{tabular}




\section{Powerworld Application}

In electrical energy systems, large amounts of system data have to be presented with innovative methods. In recent years, visualization techniques and software have developed to make data easily readable and visually appealing. One of them is the PowerWorld simulation program. Calculations can be made for different power systems using the PowerWorld simulator program. To calculate the power flow, first the desired system is drawn and the necessary input information is entered. Then the program calculates the power flow in the line with given information. PowerWorld Simulator is an interactive power systems simulation program to simulate the power systems. The software includes a highly efficient power flow analysis structure that can effectively solve a system with up to 100,000 busses $[13,14]$. The power system for the study is shown in figure 3 . The used parameters for the solution such as busses, lines, generators the same with Matlab application. The results obtained from this study is shown in the table 5 .

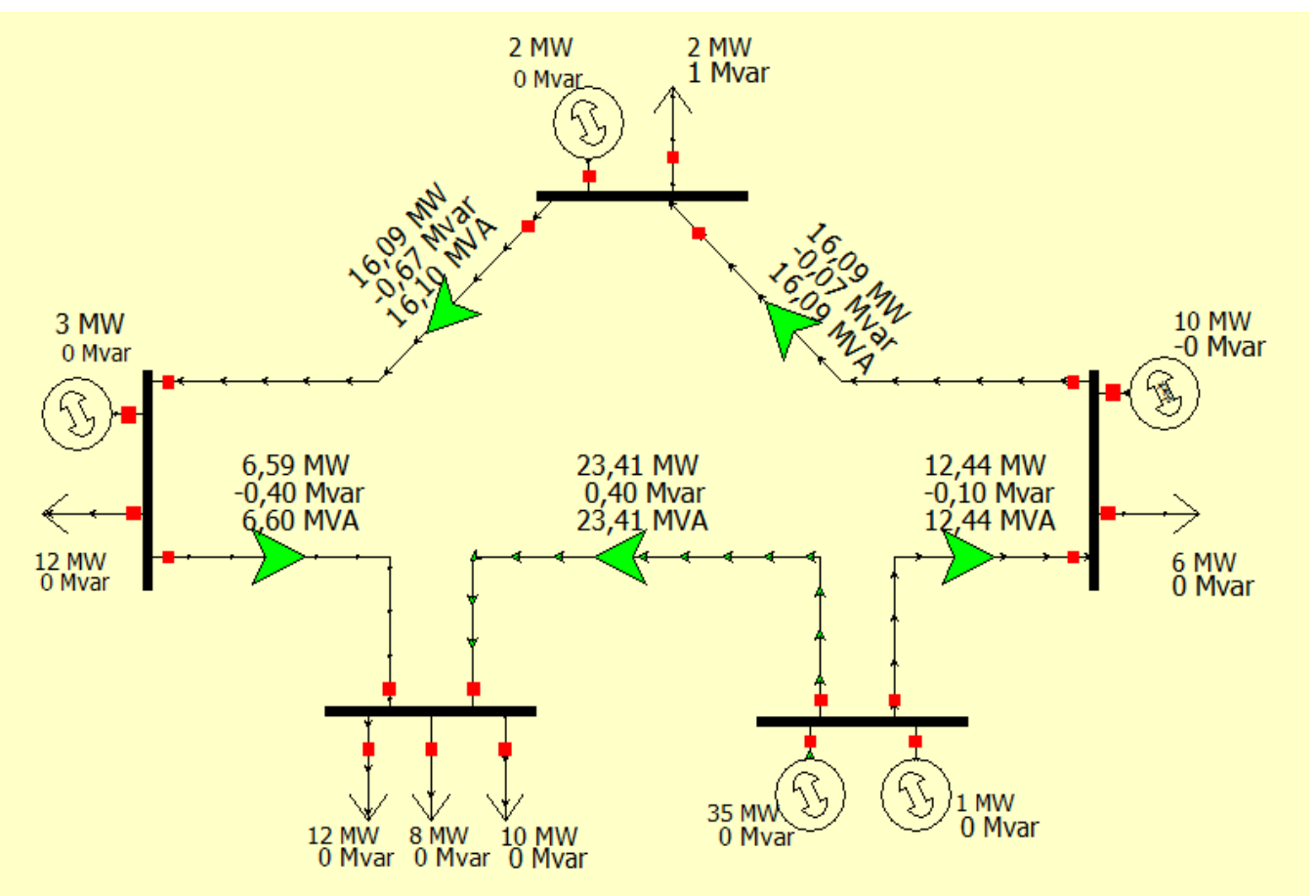

Figure 3. The Designed Power System

Table 5. Results From the PowerWorld Solution 


\begin{tabular}{|c|c|c|c|c|c|c|}
\hline \multicolumn{7}{|c|}{ Bus Flows } \\
\hline BUS & 1 BUS & 1 & 354,0 & MW & Mvar & MVA \\
\hline GENERATOH & R 1 & & &, 00 & 0,00 & 2,0 \\
\hline LOAD 1 & & & &, 00 & 0,60 & 2,1 \\
\hline TO & 2 BUS & 2 & 1 &, 09 & $-0,67$ & 16,1 \\
\hline TO & 5 Bus & 5 & -1 &, 09 & 0,07 & 16,1 \\
\hline BUS & 2 BUS & 2 & 354,0 & MW & Mvar & MVA \\
\hline GENERATOH & R 1 & & &, 54 & 0,00 & 2,5 \\
\hline LOAD 1 & & & &, 00 & 0,00 & 12,0 \\
\hline TO & 1 BUS & 1 & -1 &, 06 & 0,50 & 16,1 \\
\hline TO & 3 BUS & 3 & 1 &, 59 & $-0,50$ & 6,6 \\
\hline BUS & 3 BUS & 3 & 354,0 & $M W$ & Mvar & MVA \\
\hline LOAD 2 & & & &, 00 & 0,00 & 10,0 \\
\hline LOAD 3 & & & &, 00 & 0,00 & 12,0 \\
\hline LOAD 4 & & & &, 00 & 0,00 & 8,0 \\
\hline TO & 2 BUS & 2 & 1 &, 59 & 0,40 & 6,6 \\
\hline TO & 4 BUS & 4 & $1 \quad-2$ & .41 & -0.40 & 23.4 \\
\hline BUS & 4 BUS & 4 & 354,0 & MW & Mvar & MVA \\
\hline GENERATOH & R 1 & & &, 99 & 0,00 & 35,0 \\
\hline GENERATO & R 2 & & &, 00 & 0,00 & 1,0 \\
\hline TO & 3 BUS & 3 & 1 &, 55 & 0,10 & 23,6 \\
\hline Tо & 5 Bus & 5 & 1 &, 44 & $-0,10$ & 12,4 \\
\hline BUS & 5 Bus & 5 & 354,0 & MW & Mvar & MVA \\
\hline GENERATOH & R 1 & & & .70 & $-0,33$ & 9,7 \\
\hline LOAD 1 & & & &, 00 & 0,00 & 6,0 \\
\hline TO & 1 BUS & 1 & 1 &, 12 & $-0,25$ & 16,1 \\
\hline TO & 4 BUS & 4 & -1 & .42 & $-0,08$ & 12,4 \\
\hline
\end{tabular}

\section{Results}

Energy management is based on determining energy policies, assessing the performance of the energy management systems and ensuring improvements. Microgrids which are part of the smart grid energy systems, will spread rapidly in the coming years. In order to provide high quality and uninterrupted energy, the selected sources and loads for the microgrids should be considered and power flow analysis should be done. In this study, the power flow of a designed microgrid was obtained by PowerWorld and Matlab. As seen in the study, PowerWorld simulator has shown that the power flow analysis can be done without iterative methods. It has been seen that the PowerWolrld program is more convenient and easier for university students to better understand the course of power flow analysis.

\section{References}

[1] Shuhui L., Julio P. \& Dong Z., Microgrid Power Flow Study in Grid-Connected and Islanding Modes under Different Converter Control Strategies, Proceedings, Power and Energy Society General Meeting, San Diego, USA, 2012.

[2] Kocaman B. A Case of Energy Management Application for Microgrid, BEU Journal of Science 3, (2014), 1, pp. 35-52. 
[3] Lopes J. A., Moreira C. L., \& Madureira A. G., Defining Control Strategies for Microgrids Islanded Operation, IEEE Trans. On Power Systems, Vol. 21, (2006), 2, pp. 916-924.

[4] Satish B., Bhuvaneswari S., Control of Microgrid - A Review, Procedings, International Conference on Advances in Green Energy, Trivandrum, India, 2012

[5] Abdel-Qader, I.,. Simulation of Hybrid Power System Consisting of Wind Turbine, FV, Storage Battery and Diesel Generation Network, Master of ScienceThesis, Nablus, 2008

[6] Christine S., Advanced Architectures and Control Concepts for More Microgrids, STREP project funded by the EC under 6FP, SES6-019864, Siemens AG, Germany, 2009.

[7] Efe S. B., Cebeci M., Erdogan H., \& Ozturkmen G., A Novel Approach to Power Flow Analysis for Grid Connected Micro Grid, Proceedings, International Conference on Engineering of Modern Electric Systems, Oradea, Romania, 2015.

[8] Kaygusuz A., Gul O. \& Alagoz B.B., An Analysis for Impacts of Renewable Distributed Generation Conditions on the Load Flow Stability of Electrical Power Systems, EMO Scientific Journal, Volume 2, Issue 4, 2012

[9] Moorthy S., Al-Dabbagh M., \& Vawser M., Improved Phase-Cordinate Gauss-Seidel Load Flow Algorithm, Electric Power System Research, vol. 34, (1995), pp. 91-95,

[10] Bokka N., Comparison of Power Flow Algorithms for Inclusion in On-line Power Systems Operation Tools, Master of Science Thesis, New Orleans, USA, 2010.

[11] Eminoglu U., Developing of a New Power Flow Algorithm for Radial Distribution Systems, PhD thesis Gebze Institute of Technology, Turkey, 2007

[12] Glover J.D., \& Sarma M.,. Power System Analysis and Design (Second Edition), PWS Publishing Company,Boston, USA, pp. 252-292, 1994

[13] Klump R.P., Wu W., \& Dooley G., Displaying Aggregate Data, Interrelated Quantities, and Data Trends in Electric Power Systems, Proceedings, International Conference on System Sciences, Hawaii, USA, 2002

[14] Dong Z., \& Shuhui L., Solving Optimal Dispatch Problem for a Competitive Wholesale Power Market by using PowerWorld, Proceedings, Power and Energy Society General Meeting, Vancouver, Canada, 2013 